\title{
Contribution of mechanosensitive channels to osmoadaptation and ectoine excretion in Halomonas elongata
}

\author{
Jasmina Vandrich $^{1,3} \cdot$ Friedhelm Pfeiffer $^{2} \cdot$ Gabriela Alfaro-Espinoza $^{1,4} \cdot$ Hans Jörg Kunte $^{1}$
}

Received: 28 November 2019 / Accepted: 24 March 2020 / Published online: 7 April 2020

(c) The Author(s) 2020

\begin{abstract}
For osmoadaptation the halophilic bacterium Halomonas elongata synthesizes as its main compatible solute the aspartate derivative ectoine. H. elongata does not rely entirely on synthesis but can accumulate ectoine by uptake from the surrounding environment with the help of the osmoregulated transporter TeaABC. Disruption of the TeaABC-mediated ectoine uptake creates a strain that is constantly losing ectoine to the medium. However, the efflux mechanism of ectoine in H. elongata is not yet understood. $H$. elongata possesses four genes encoding mechanosensitive channels all of which belong to the small conductance type (MscS). Analysis by qRT-PCR revealed a reduction in transcription of the $m s c S$ genes with increasing salinity. The response of $H$. elongata to hypo- and hyperosmotic shock never resulted in up-regulation but rather in downregulation of $m s c S$ transcription. Deletion of all four $m s c S$ genes created a mutant that was unable to cope with hypoosmotic shock. However, the knockout mutant grew significantly faster than the wildtype at high salinity of $2 \mathrm{M} \mathrm{NaCl}$, and most importantly, still exported $80 \%$ of the ectoine compared to the wildtype. We thus conclude that a yet unknown system, which is independent of mechanosensitive channels, is the major export route for ectoine in H. elongata.
\end{abstract}

Keywords Halomonas elongata $\cdot$ Ectoine $\cdot$ Mechanosensitive channel $\cdot \mathrm{MscS} \cdot \mathrm{MscK} \cdot$ Osmoadaptation $\cdot$ Solute excretion $\cdot$ Osmotic shock

Communicated by S. Albers.

Electronic supplementary material The online version of this article (https://doi.org/10.1007/s00792-020-01168-y) contains supplementary material, which is available to authorized users.

Gabriela Alfaro-Espinoza

aespinoza@mpimp-golm.mpg.de

$\triangle$ Hans Jörg Kunte

hans-joerg.kunte@bam.de

1 Division Biodeterioration and Reference Organisms, Bundesanstalt für Materialforschung und -prüfung, Berlin, Germany

2 Computational Biology Group, Max-Planck-Institute of Biochemistry, Martinsried, Germany

3 Present Address: Research Coordination, German Federal Institute for Risk Assessment, Berlin, Germany

4 Present Address: Systems and Synthetic Metabolism Group, Max-Planck-Institute of Molecular Plant Physiology, Potsdam, Germany

\section{Introduction}

To allow for survival in high saline environments, many Bacteria and Archaea accumulate organic compounds like sugars, amino acids, and/or their derivatives to serve as osmolytes (Galinski 1995; Roberts 2005; Widderich et al. 2016). These highly water-soluble molecules do not interfere with the cell's metabolism and are, therefore, called compatible solutes (Brown 1976). Cells can amass compatible solutes in their cytoplasm in molar concentrations either by de novo synthesis (Galinski 1995; Klähn and Hagemann 2011; Kuhlmann and Bremer 2002; Peters et al. 1990) or by uptake from the medium through osmoregulated transporters (Farwick et al. 1995; Kempf and Bremer 1998; Kunte 2006; Mikkat et al. 1997; Wood 1999; Wood et al. 2001, 2005). A sudden decrease in salt concentration (e.g., rainfall) will lead to a massive water influx into the cell, with a concomitant increase in cell turgor. To avoid cell disruption, the cytoplasmic membrane contains mechanosensitive channels, which act as emergency valves (Martinac 2001). These mechanosensitive channels are stretch-activated pores and open in response to an increase in membrane tension. Their opening 
allows for a rapid, non-specific release of cytoplasmic, low molecular-weight solutes. Different classes of mechanosensitive channels exist in various bacteria, which are defined according to their pore size and gating behavior (Cox et al. 2018). The most important mechanosensitive channels are the channels of large (MscL) and small (MscS) conductivity and were originally described in Escherichia coli (Berrier et al. 1996). The MscS family is more widely spread in Bacteria (Pivetti et al. 2003) and many halophilic bacteria possess no mechanosensitive channels of the MscL-type. This led to the speculation that the loss of MscL is an adaptation to saline environments (Penn and Jensen 2012).

The halophilic gamma-proteobacterium Halomonas elongata can tolerate salt concentrations well above $1.7 \mathrm{M} \mathrm{NaCl}$ $(100 \mathrm{~g} / \mathrm{L})$ (Vreeland et al. 1980) and accumulates the compatible solute ectoine for osmoadaptation (Göller et al. 1998; Ono et al. 1999). Interestingly, ectoine functions not only as an osmoregulatory compatible solute but also protects cell components (membranes, proteins, DNA) and even whole cells against different stressors such as freezing and thawing, high temperatures, drying and UV-light (Bünger et al. 2001; Kolp et al. 2006; Lippert and Galinski 1992; Zaccai et al. 2016). It also protects lung epithelia against nanoparticle-induced inflammation (Sydlik et al. 2009), and damage to the small bowel from ischaemia and reperfusion injury (Wei et al. 2009). Recently, it was shown that ectoine is a potent protector of DNA against ionizing radiation (Schröter et al. 2017). Its protective properties make ectoine a valuable compound and ectoine is marketed in health care and skin care products worldwide (Kunte et al. 2014; Lentzen and Schwarz 2006). Thus, ectoine is produced annually on a scale of tons by industry in a biotechnological process with H. elongata used as producer strain (Kunte et al. 2014).

Halomonas elongata amasses ectoine in the cytoplasm either by synthesis via a pathway utilizing enzymes specified by three genes, ectABC (Göller et al. 1998), or by uptake via the ectoine-specific osmoregulated transporter TeaABC (Grammann et al. 2002; Kuhlmann et al. 2008; Schweikhard et al. 2010). TeaABC is not only required for the osmoregulatory accumulation of external ectoine, but also counterbalances a mechanism responsible for excreting endogenous ectoine from the cell (Grammann et al. 2002; Kunte 2006). The mechanism was discovered based on the finding that mutant strains of $H$. elongata with an inoperable TeaABC transporter constantly release ectoine to the surrounding medium (Grammann et al. 2002; Kunte et al. 2002). Still these mutants can keep the cytoplasmic ectoine concentration at the same level as the wild-type strain. Apparently, the mutation of $t e a A B C$ not only causes ectoine excretion to the medium but results in overproducing ectoine. This observation led to the hypothesis that TeaABC-mediated ectoine uptake and the release of internal ectoine is linked to regulating ectoine synthesis (Kunte 2006). However, the mechanism by which ectoine is released from the cell is yet unknown.

Börngen et al., working on Corynebacterium glutamicum, presented results that argued for a mechanism of fine-tuning the internal compatible solute concentration of glycinebetaine by cooperation of an active uptake via transporter BetP and a passive, but regulated efflux via mechanosensitive channels of the MscS-type (Börngen et al. 2010). However, the MscS variant of $C$. glutamicum differs structurally from $\mathrm{MscS}$ of other bacteria and it is, therefore, debated whether the export via mechanosensitive channels (MS channels) in bacteria is a wide-spread mechanism in finetuning the cell's compatible solute concentration. In contrast to $C$. glutamicum, none of the known MscL- and MscStype of MS channels in B. subtilis participate in export of the endogenous compatible solute proline (Hoffmann et al. 2012). Moreover, in osmotically adapted $E$. coli cells export of the compatible solutes ectoine and hydroxyectoine is also independent of MS channels (Czech et al. 2016).

Halomonas elongata possesses four genes encoding MS channels, which all belong to the MscS-family. The objective of this research was to determine the role of MS channels for osmoadaptation in H. elongata and in excreting ectoine from the cell. We performed transcriptional analyses of the MS channel genes and generated a mutant, which lacks all MS channel genes. Subsequently, each of the individual genes was subjected to analysis after reinsertion into the genome. These genetic modifications were performed in parallel in wildtype and in the $t e a A B C$ deletion mutant. Our results show that mechanosensitive channels play only a minor role in ectoine excretion.

\section{Materials and methods}

\section{Bacterial strains and growth conditions}

Bacterial strains are listed in Suppl. Table 1. Escherichia coli DH5 $\alpha$ cells were grown overnight at $37^{\circ} \mathrm{C}$ in Luria-Bertani (LB medium). Generally, all strains of Halomonas elongata were grown aerobically at $30{ }^{\circ} \mathrm{C}$ in MM63 minimal medium (Larsen et al. 1987) with glucose as the carbon source and at various $\mathrm{NaCl}$ concentrations. Growth curves were recorded in a volume of $200 \mu \mathrm{l}$ in 96 well plates with a plate reader (BioTek Synergy HT). For analyzing ectoine and glucose concentration in growth medium, $H$. elongata KB2.13 and KB2.13-MSC were grown in MOPS minimal medium (0.05 M glucose, $0.07 \mathrm{M} \mathrm{NH}_{4} \mathrm{Cl}, 0.017 \mathrm{M} \mathrm{KH}_{2} \mathrm{PO}_{4}, 0.02 \mathrm{M}$ $\mathrm{K}_{2} \mathrm{SO}_{4}, 0.1 \mathrm{M}$ MOPS, $5 \mu \mathrm{M} \mathrm{Na}_{2}$-EDTA, $3.2 \mathrm{mM} \mathrm{MgSO}_{4}$, $0.1 \mathrm{mM} \mathrm{FeSO}_{4}, \mathrm{NaCl}$ as indicated in the experimental setting, $\mathrm{pH} 7$ ). 


\section{Salt-shock experiments}

Halomonas elongata was grown in MM63 minimal medium supplemented with $1 \mathrm{M} \mathrm{NaCl}$ until $\mathrm{OD}_{600}$ reached 0.8 . For hypoosmotic and hyperosmotic shock, the cultures were diluted sixfold in fresh media to $0.1 \mathrm{M} \mathrm{NaCl}$ or $2 \mathrm{M} \mathrm{NaCl}$, respectively. Cell viability was monitored by constant recording of the $\mathrm{OD}_{600}$ and counting of colony forming units in spotting assays.

\section{Construction of vectors for gene deletion or insertion}

For gene deletion, DNA sequences $1 \mathrm{~kb}$ upstream and downstream from the gene of interest were amplified with $20 \mathrm{nt}$ overhangs and fused into the shuttle vector pK18mobsacB or pK19mobsacB (Schäfer et al. 1994) applying Gibson assembly according to the manufacturer's instruction (New England Biolabs). For gene insertion the gene of interest plus $1 \mathrm{~kb}$ upstream and downstream were amplified and fused into the shuttle vector with Gibson assembly. All vectors are listed in Suppl. Table 2 and the corresponding primers used for the amplification of fragments are listed in Suppl. Table 3. The primers M13fwd and M13rev were used to check the inserts by PCR amplification and DNA sequencing.

\section{Generation of deletion and insertion mutants}

Plasmid pK18mobsacB or pK19mobsacB carrying the corresponding DNA for deletion and insertion, respectively, were transformed into $E$. coli ST18. The plasmids were transferred into $H$. elongata via biparental conjugation (Alfaro-Espinoza and Ullrich 2015; Kunte and Galinski 1995). Fresh overnight cultures of $E$. coli ST18, carrying the corresponding plasmid, and of $H$. elongata were mixed in a ratio of 1:2 and $20 \mu \mathrm{l}$ drops were spotted on LB agar plates supplemented with L-aminolevulinic acid (Sigma-Aldrich). After $24 \mathrm{~h}$ incubation at $30^{\circ} \mathrm{C}$, cells were scratched from the plate, resuspended in LB medium and vortexed for $10 \mathrm{~min}$. The cell suspension was diluted, plated on LB medium plus the respective antibiotic and incubated overnight at $30^{\circ} \mathrm{C}$. Deletion mutants, arising after double cross-over, were then selected for on LB medium containing $22 \%$ (w/v) sucrose at $37^{\circ} \mathrm{C}$. The deletion and insertion sites were verified by PCR and DNA-sequencing.

\section{RNA extraction}

RNA extraction was performed with RP-CTAB buffer (3 mM EDTA, $700 \mathrm{mM} \mathrm{NaCl}, 40 \mathrm{mM}$ DTT) and hot SDSbuffer ( $3 \mathrm{mM}$ EDTA, $700 \mathrm{mM} \mathrm{NaCl}, 2 \%$ (w/v) SDS) followed by Phenol-Chloroform extraction (Schenk et al.
2008). After extraction, the RNA was treated with TURBO DNA-free Kit (Life technologies).

\section{qRT-PCR}

Gene transcription analysis was performed using the iTaq $^{\mathrm{TM}}$ Universal SYBR ${ }^{\circledR}$ Green One-Step Kit on Stratagene Mx3005P Quantitative PCR System. Three biological and three technical replicates were used per treatment. All qRT-PCR primers (Suppl. Table 4) were selected to keep amplification efficiency in an optimum range of $95-105 \%$. Normalized relative expression (NRE) values were calculated according to the PFAFFL method (Pfaffl 2001) in relation to the reference gene $r e c A$. Gene $r e c A$ was chosen from 8 putative reference genes $(16 \mathrm{~S}$, gyrA, gyrB, lys A, recA, rho, $r p o A, r p o B$ ) after testing for stable expression, suitability and efficiency according to published recommendations of Kozera and Rapacz (2013) and based on the proteome data of $H$. elongata, which were collected from cells grown at various salt concentrations (Kindzierski et al. 2017). The one-way ANOVA (ANalysis Of VAriance) with post-hoc Tukey HSD (Honestly Significant Difference) test was used to evaluate significance.

\section{Glucose quantification}

The dinitrosalicyclic acid method (Miller 1959) has been applied to $200 \mu \mathrm{l}$ volume in microtiter plates. $100 \mu \mathrm{l}$ dinitrosalicylic acid reagent $(1 \%(\mathrm{w} / \mathrm{v})$ dinitrosalicylic acid, $1.5 \%(\mathrm{w} / \mathrm{v}) \mathrm{NaOH}, 40 \%(\mathrm{w} / \mathrm{v})$ potassium sodium tartrate, $2 \%\left(\mathrm{w} / \mathrm{v}\right.$ ) phenol, $0.5 \%(\mathrm{w} / \mathrm{v}) \mathrm{Na}_{2} \mathrm{SO}_{4}$ ) was added to $100 \mu \mathrm{l}$ of cell culture supernatant. The mixture was heated at $95{ }^{\circ} \mathrm{C}$ for $5 \mathrm{~min}$ and the $\mathrm{OD}_{575}$ was recorded with a plate reader (BioTek Synergy HT).

\section{HPLC analysis of ectoine}

For HPLC analysis, H. elongata was grown at $33^{\circ} \mathrm{C}$, shaking with $220 \mathrm{rpm}$ in MOPS minimal medium with $\mathrm{NaCl}$ concentrations as indicated in the experimental setting. The samples were centrifuged for $5 \min$ at $4{ }^{\circ} \mathrm{C}$ and $4000 \times g$. The supernatant was filtered to remove cell debris and then analyzed without further dilution or treatment. The ectoine content of the samples was measured by ultra-high-performance liquid chromatography (U-HPLC) on an Agilent Technologies 1290 Infinity HPLC-system using a reverse-phase column (GromSil 100 Amino-1 PR, $3 \mu \mathrm{m}$ ) and applying an acetonitrile $/ \mathrm{H}_{2} \mathrm{O}$ gradient as mobile phase. The absorption of ectoine was recorded at $207 \mathrm{~nm}$ using an UV-detector (Kuhlmann and Bremer 2002). 


\section{Bioinformatic analyses}

There are four annotated mechanosensitive channels in the H. elongata genome ( $m s c S$ : HELO_3171, HELO_3378, HELO_4248; mscK: HELO_2045) (Pfeiffer et al. 2017; Schwibbert et al. 2011). We made two attempts to search for additional, yet unannotated mechanosensitive channels. (a) We downloaded the entry for each mechanosensitive channel of Escherichia coli (mscS-related: UniProt P0C0S1 mscS, P77338 mscK, P39285 mscM, POAEB5 ynaI, P75783 ybiO, P0AAT4 mscM; mscL-related: P0A742 mscL) (Berrier et al. 1996) and of Corynebacterium glutamicum (Cgl0879 mscL UniProt:Q8NS07; Cgl1270 yggB UniProt:P42531; KIQ_000100 UniProt:A0A072ZAU2) (Börngen et al. 2010; Nottebrock et al. 2003) for subsequent BLASTp analyses. All BLASTp results either retrieved the already annotated mechanosensitive channels or did not identify homologs. (b) We searched in InterPro (https://www.ebi.ac.uk/interpro) for "mechanosensitive" and retrieved 16 InterPro domains related to mechanosensitive channels (plus the domain from one toxin that inactivates mechanosensitive channels). The domain codes were then used to search the $H$. elongata proteome in UniProt. Of these, 8 domains (IPR006685, IPR023408, IPR011066, IPR011014, IRP006686, IPR025692, IPR024393, IPR008910) retrieved the 4 annotated mechanosensitive channels (or subsets thereof). One domain (IPR010920, "LSM domain superfamily") retrieved the same set plus, in addition, Hfq (HELO_3364). This is the expected behavior according to the InterPro domain annotation. The other 7 domains (IPR036019, IPR001185, IPR019823, IPR037673, IPR016688, IPR030192, IPR031334) did not retrieve entries from H. elongata. From this analysis, we concluded that the exhaustive set of mechanosensitive channels of $H$. elongata is represented by the four genes which are annotated accordingly.

\section{Results}

\section{Identification of MS channels in H. elongata}

In the genome of $H$. elongata, four MS channels are annotated. Three are annotated as $m s c S$ and one as $m s c K$ (Table 1, Suppl. Figures 1, 2, 3). MscK was formerly annotated as potassium efflux system KefA (Cox et al. 2015). Additional MS channels could not be identified by BLASTp analysis with MS channel proteins from Corynebacterium glutamicum (Börngen et al. 2010; Nottebrock et al. 2003) and from E. coli (Berrier et al. 1996). In addition, no additional H. elongata proteins contain any of the InterPro domains, which are associated with MS channels. Thus, the analysis of the four MS channels as listed in Table 1 was considered to be exhaustive.

\section{Transcription levels of MS channel genes at optimum, low, and high salt}

We quantified transcription levels of all MS channel genes by qRT-PCR with expression of $r e c A$ as a reference. First, transcription was accessed for cells grown at optimum conditions of $1 \mathrm{M} \mathrm{NaCl}$ in minimal medium (Fig. 1). The $m s c S 1$ gene was strongly expressed (38-fold in relation to recA), while only moderate to small amounts of transcript were found for $m s c S 2$ (fivefold), $m s c K$ (fourfold) and $m s c S 3$ (onefold).

Next, we determined transcription levels from cells grown at low, medium and high salt conditions. For low salt stress, cells were grown at $0.1 \mathrm{M} \mathrm{NaCl}$, which is below the lower range of preferable salt requirements of $1 \mathrm{M} \mathrm{NaCl}$ for $H$. elongata. For high salt stress, cells were grown at $2 \mathrm{M} \mathrm{NaCl}$. At low salt stress conditions, transcription of $m s c S 3$ and $m s c K$ was significantly upregulated compared to optimal
Table 1 Mechanosensitive channels in $H$. elongata

\begin{tabular}{llllll}
\hline Gene & Code & Length & MscS core region & Homolog & Extra InterPro domains \\
\hline mscK & Helo_2045 & 1173 & $873-1127$ & MCSK_ECOLI (37\%) & IPR024393; IPR025692 \\
mscS1 & Helo_3378 & 281 & $16-268$ & MSCS_ECOLI (43\%) & - \\
mscS2 & Helo_4248 & 780 & $465-718$ & YBIO_ECOLI (36\%) & none \\
mscS3 & Helo_3171 & 770 & $467-723$ & Helo_4248 (28\%) & none \\
\hline
\end{tabular}

In the column "Homolog" the best full-length homolog from the analyzed set of proteins is given, with protein sequence identity indicated in parenthesis. Helo_3171 is more closely related to Helo_4248 than to any of the MscS-related proteins from E. coli. All four H. elongata proteins have the MscS core region as indicated. For an alignment of this region see Suppl. Figure 1. Most of this region is covered by the InterPro MscS core domain (IPR006685, "MscS_channel"). This domain is split into three consecutive subdomains (IPR011014 “MscS_channel_TM-2"; IPR010920 "LSM_dom_sf”; IPR011066 "MscC_channel_C"). The region covered by LSM may have two additional domain assignments (IPR006686 "MscS_channel_CS"; IPR023408 "MscS_dom_sf"). MscK has additional domains in the N-terminal region ("Extra InterPro domains": IPR024393 "MscS_porin"; IPR025692 "MscS_IM_dom1") (alignment in Suppl. Figure 3). The N-terminal regions of Helo_4248 and Helo_3171 (ca 460 aa) are homologous but have no InterPro domain assigned ("none") (alignment in Suppl. Figure 2) 


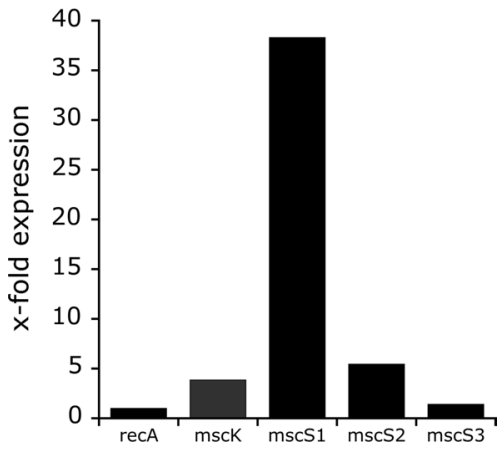

Fig. 1 Transcripts of MS channel genes $m s c K, m s c S 1, m s c S 2$, and $m s c S 3$ from $H$. elongata cells grown in MM63 minimal medium at $1 \mathrm{M} \mathrm{NaCl}$. Transcript levels are depicted as $\mathrm{x}$-fold expressions in relation to the reference gene $r e c A$. Data presented are from three independent experiments (three biological replicates). Each experiment was measured three times (three technical replicates)

salinity of $1 \mathrm{M} \mathrm{NaCl}$ (Fig. 2). In addition, for $m s c S l$ and $m s c S 2$, higher transcription values were measured at low salt, but significance was not reached. Comparing transcription at low salt to high salt-stress, both, $m s c K$ and $m s c S 1$, were significantly upregulated at low salt (Fig. 2). Taken together, and surprisingly, transcription of MS channel genes tends to decrease with increasing salt concentrations.

Next, we were interested in transcriptional changes of MS channel genes upon osmotic shock. When salt concentration rises, potassium is pumped into the cells of $H$. elongata via TrkH and TrkI transporters and compatible solutes are gathered (Kraegeloh et al. 2005; Kraegeloh and Kunte 2002). When cells are subsequently exposed to a rapid downshift in salinity, the influx of water may cause an increase of turgor until bursting, unless the cell is able to discharge ions

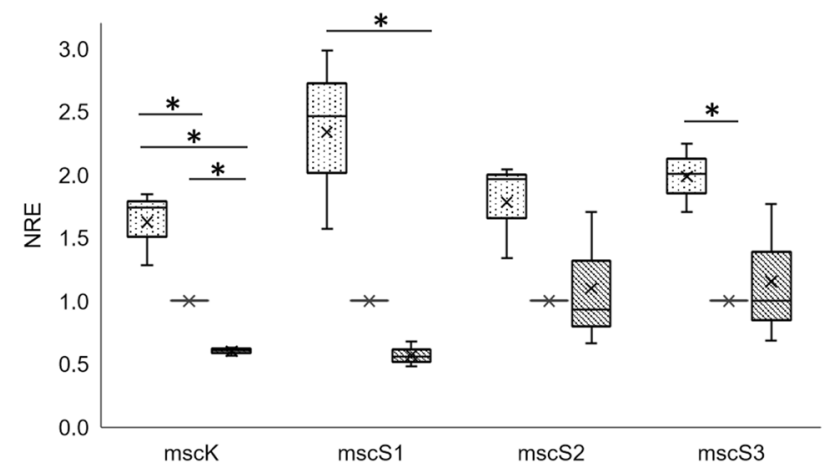

Fig. 2 Relative transcription levels of MS channel genes depending on the salinity of the medium. H. elongata wildtype was grown in MM63 with $0.1 \mathrm{M} \mathrm{NaCl}$ (light grey) and MM63 with $2 \mathrm{M} \mathrm{NaCl}$ (dark grey). Results are depicted in relation to the optimum salt concentration of $1 \mathrm{M} \mathrm{NaCl}$ (set to 1). Data presented are from three independent experiments (three biological replicates). Each experiment was measured three times (three technical replicates). Asterisk mark significance $(p$ value $<0.05)$ between samples and compatible solute quickly. MS channels are responsible for this unspecific release of small, soluble molecules from the cytoplasm. Transcription of MS channel genes was measured for a downshock (hypoosmotic shock) from 1 to $0.1 \mathrm{M} \mathrm{NaCl}$ but also for an upshock (hyperosmotic shock) in salinity from 1 to $2 \mathrm{M} \mathrm{NaCl}$. The transcription levels were recorded $30 \mathrm{~min}$ and $15 \mathrm{~min}$ before the shock and $15 \mathrm{~min}$ and $30 \mathrm{~min}$ after the shock. In case of an osmotic downshock from 1 to $0.1 \mathrm{M} \mathrm{NaCl}$, the amount of transcripts from all four channels remained unchanged (Table 2, Suppl. Figure 4). In contrast, the three MS channels genes $m s c K, m s c S 1$ and $m s c S 3$ responded with downregulation to a hyperosmotic shock (Table 2, Suppl. Figure 4), which is in agreement with downregulation observed in adapted cell for $m s c S 1$ and $m s c K$ (Fig. 2). Gene $m s c S 2$ was not significantly downregulated after upshock from 1 to $2 \mathrm{M} \mathrm{NaCl}$.

\section{Deletion of all MS channel genes in $H$. elongata}

All four genes coding for MS channels were deleted from the H. elongata DSM $2581^{\mathrm{T}}$ wildtype genome (see "Material and Methods"). Gene deletions were validated by PCR analysis and DNA sequencing. The resulting mutant strain lacking all MS channel genes was designated $H$. elongata MSC-1324 ( $\Delta m s c K, \Delta m s c S 1, \Delta m s c S 2, \Delta m s c S 3)$.

\section{Growth of $H$. elongata wildtype and mutant MSC-1324 at different salt concentrations}

It was assessed whether the growth of H. elongata MSC1324 varies from the parental wildtype strain, when grown at different salt concentrations. The deletion of all MS channel genes might influence the growth in extreme salt concentrations due to alterations of the adjustment mechanism for intracellular substances and ectoine concentration.

The growth rate of the MSC-1324 mutant was very similar to that of the wildtype at low and medium salinity (Table 3; Fig. 3a, b) and at all salinities the wildtype and the MSC-1324 mutant reached the same final optical density. At high salinity of $2 \mathrm{M} \mathrm{NaCl}$, however, MSC-1324 grew

Table 2 Transcriptional regulation of MS channel genes in response to osmotic shock

\begin{tabular}{lll}
\hline & $\begin{array}{l}\text { Hypoosmotic shock from 1 to } \\
0.1 \mathrm{M} \mathrm{NaCl}\end{array}$ & $\begin{array}{l}\text { Hyperosmotic shock } \\
\text { from 1 to 2 M NaCl}\end{array}$ \\
\hline $\mathrm{MscK}$ & - & $\downarrow$ \\
$\mathrm{MscS} 1$ & - & $\downarrow$ \\
$\mathrm{MscS} 2$ & - & - \\
$\mathrm{MscS} 3$ & - & $\downarrow$ \\
\hline
\end{tabular}

(-) no regulation, $(\downarrow)$ significant downregulation

For further details see Suppl. Figure 1 in Supplementary Material 
Table 3 Growth parameters of $H$. elongata DSM $2581^{\mathrm{T}}$ (wildtype) and MS channel mutant MSC-1324

\begin{tabular}{|c|c|c|c|c|c|c|c|c|}
\hline \multirow[t]{2}{*}[\mathrm{NaCl}]{} & \multicolumn{2}{|c|}{ Growth rate $\left[h^{-1}\right]$} & \multicolumn{2}{|c|}{ Generation time $[h]$} & \multicolumn{2}{|c|}{ Max $\mathrm{OD}_{600}$} & \multicolumn{2}{|c|}{$t\left(\max \mathrm{OD}_{600}\right)[h]$} \\
\hline & $\mathrm{Wt}$ & MSC-1324 & $\mathrm{Wt}$ & MSC-1324 & $\mathrm{Wt}$ & MSC-1324 & $\mathrm{Wt}$ & MSC-1324 \\
\hline $0.1 \mathrm{M}$ & 0.22 & 0.26 & 3.09 & 2.71 & 1.04 & 1.04 & 32 & 38 \\
\hline $1.0 \mathrm{M}$ & 0.38 & 0.41 & 1.84 & 1.69 & 1.40 & 1.39 & 60 & 60 \\
\hline $2.0 \mathrm{M}$ & 0.24 & 0.30 & 2.88 & 2.33 & 1.28 & 1.29 & 48 & 48 \\
\hline
\end{tabular}

Growth rate, generation time and maximal optical density at $600 \mathrm{~nm}\left(\mathrm{OD}_{600}\right)$ were compared. Both strains were grown in MM63 medium at low $(0.1 \mathrm{M} \mathrm{NaCl})$, medium $(1 \mathrm{M} \mathrm{NaCl})$, and high salt $(2 \mathrm{M} \mathrm{NaCl})$. Data presented are from three independent experiments (three biological replicates). Each experiment was measured 9 times ( 9 technical replicates)
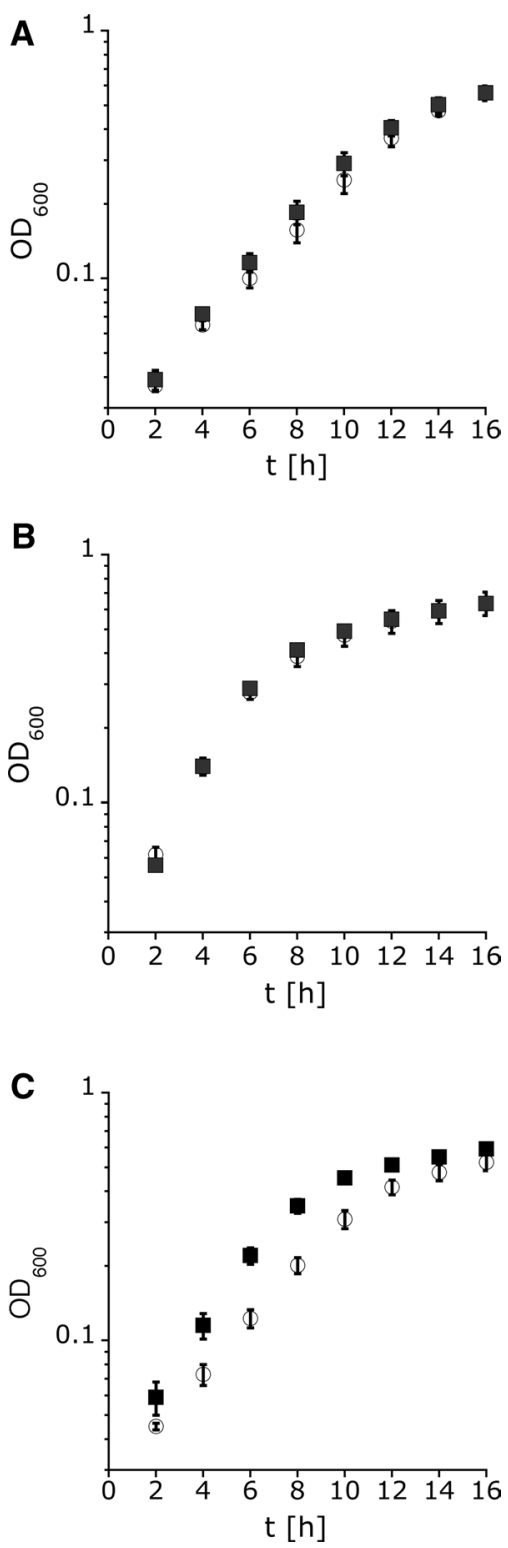

Fig. 3 Growth of $H$. elongata MSC-1324 depending on the salinity of the growth medium. Growth of $H$. elongata wildtype (white) and mutant MSC-1324 (black) was assessed at a $0.1 \mathrm{M} \mathrm{NaCl}$, b $1 \mathrm{M}$ $\mathrm{NaCl}$, and $\mathbf{c} 2 \mathrm{M} \mathrm{NaCl}$ in MM63 minimal medium until onset of stationary phase. Data shown are the mean from three biological and 9 technical replicates significantly faster than the wildtype (Fig. 3c). The growth advantage of mutant MSC-1324 is consistent with our finding that MS channels genes are downregulated in wildtype cells at high salt. Apparently, MS channels pose a burden for salt-stressed cells of $H$. elongata and it is, therefore, meaningful to downregulate them at high salt.

\section{Significance of MS channels for adaptation of $H$. elongata to hypoosmotic shock}

MS channels are known to act as emergency valves, when cells must cope with sudden dilution of salt water by rainfall or flooding (hypoosmotic shock) (Berrier et al. 1992; Levina et al. 1999; Oren 2002). We investigated the behavior of H. elongata MSC-1324 compared to the wildtype following an osmotic downshock and monitored the survival by total cell count $\left(\mathrm{OD}_{600}\right)$ and live cell count. Finally, the contribution of each MS channel for the survival of $H$. elongata was assessed. For this, we restored each single MS channel gene in the quadruple MS channel deletion mutant $\mathrm{H}$. elongata MSC-1324. The corresponding MS channel gene was transferred into the mutant strain via the conjugative plasmid pK18mobsacB (Schäfer et al. 1994) and placed at its original genomic position by homologous recombination. Correct insertion of the genes was verified by PCR and DNA sequencing.

All mutant strains and the wildtype were exposed to hypoosmotic shock. Following hypoosmotic shock, the optical density of the wildtype culture dropped by approximately $25 \%$, while the optical density of the MS channel mutant MSC-1324 dropped by approximately 50\% (Fig. 4). Cell counting revealed that $10 \%$ of the wildtype cells survived a downshock from 1 to $0.1 \mathrm{M} \mathrm{NaCl}$, but the major part of the mutant cells, which are unable to release the excess of solutes, burst during osmotic downshock (Fig. 5a). Only $0.1 \%$ of the mutant cells survived such a downshock. The wildtype recovered quickly and proceeded to grow. Growth of the mutant halted for the entire observation time after the shock (Fig. 4).

We next analyzed the survival after hypoosmotic shock and growth behavior of the mutants expressing only one of 


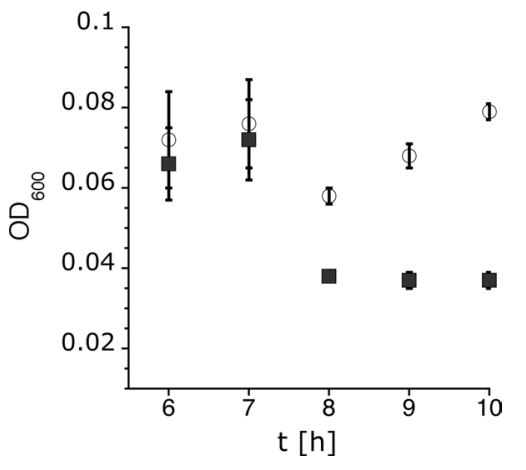

Fig. 4 Survival of $H$. elongata wildtype and MS channel mutant MSC-1324 ( $\Delta m s c K, \Delta m s c S 1, \Delta m s c S 2, \Delta m s c S 3)$ after hypoosmotic shock. The optical density was monitored to trace the survival of wildtype $H$. elongata DSM $2581^{\mathrm{T}}$ white) and mutant $H$. elongata MSC-1324 (black) after an hypoosmotic shock from 1 to $0.1 \mathrm{M} \mathrm{NaCl}$. For osmotic shock, cultures were diluted in fresh media (1:6). The OD values before shock were normalized accordingly. The osmotic shock was applied after seven and a half hours $(7.5 \mathrm{~h})$. Data presented are from three independent experiments (three biological replicates). Each experiment was measured three times (three technical replicates)

the four MS channel genes to assess the biological function and relevance of each channel. The three MS channels, MscK, MscS2, and MscS3, individually were able to restore the wildtype level of survival, with $10 \%$ of the cells surviving hypoosmotic shock (Fig. 5a). Likewise, the mutant cells resumed growth after shock similar to the wildtype (data not shown). However, inserting gene mscSI (Helo_3378) resulted in only partial complementation and the mutant strain was still severely impaired in stress adaptation. Only $1 \%$ of the cells survived the shock. The surviving cells also recovered significantly slower compared to the wild type (Fig. 5b) and compared to the complemented strains carrying any of the other MS channel genes. Taken together, reinserting the MS channel genes restored the wild type phenotype partially $(m s c S 1)$ or completely $(m s c K, m s c 2$, $m s c 3$ ), which proved that all four genes are functional in H. elongata.

\section{Deletion of all MS channel genes in ectoine excretion mutant KB2.13}

The ectoine excretion strain KB2.13 ( $\triangle$ doeA, $\triangle t e a A B C)$ (Schwibbert et al. 2011) is leaking ectoine continuously to the medium. Strain KB2.13 is deficient in osmoregulatory uptake of ectoine $(\triangle t e a A B C)$ and unable to degrade ectoine $(\triangle d o e A)$, which contributes to an increased ectoine excretion. All four MS channel genes were deleted in strain $\mathrm{KB} 2.13$, identically to the procedure in the wildtype strain (see above). As before, the mutation sites were checked by PCR and DNA sequencing. The quadruple MS channel mutant derived from KB2.13 was named $H$. elongata
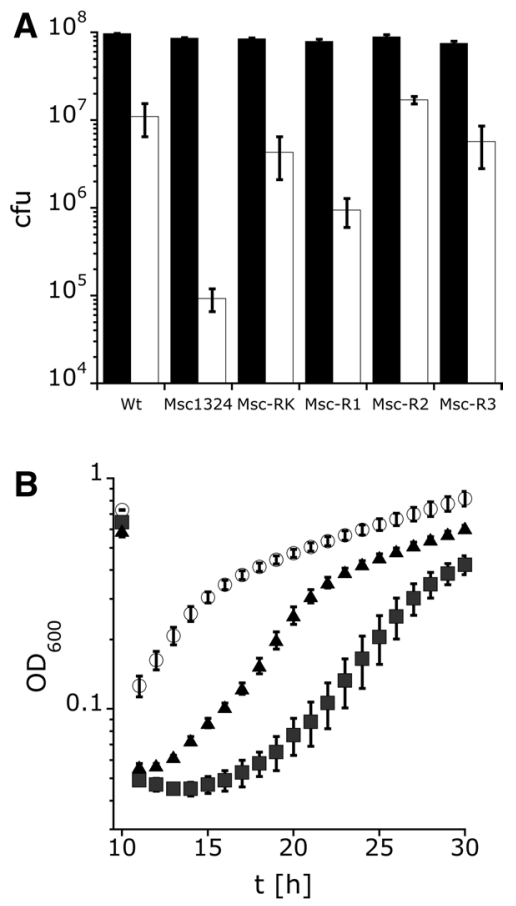

Fig. 5 Survival after osmotic shock of $H$. elongata wildtype (wt) compared to $H$. elongata strains carrying only one MS channel gene. a Live cells have been counted before (black) and after osmotic shock (white). b Recovery of growth after hypoosmotic has been monitored for the H. elongata wildtype (white), strain MSC-1324 (black squares) and strain MSC-R1 (black triangles). All other complemented mutants behaved liked the wildtype (data not shown). H. elongata MSC-1324 ( $\Delta m s c K, \Delta m s c S 1, \Delta m s c S 2, \Delta m s c S 3)$, H. elongata MSC-RK $\left(m s c K^{+}, \Delta \mathrm{mscS} 1, \Delta m s c S 2, \Delta m s c S 3\right), H$. elongata MSC-R1 ( $\left.m s c S 11^{+}, \Delta m s c K, \Delta m s c S 2, \Delta m s c S 3\right), H$. elongata MSC-R2 $\left(m s c S 2^{+}, \Delta m s c K, \Delta \mathrm{mscS} 1, \Delta m s c S 3\right), H$. elongata MSC-R3 (mscS3 ${ }^{+}$, $\Delta m s c K, \Delta \mathrm{mscS} 1, \Delta m s c S 2)$. Data presented are from three independent experiments (three biological replicates). Each experiment was measured three times (three technical replicates, 5A) and 9 times (5B), respectively

KB2.13-MSC ( $\triangle$ doeA, $\Delta$ teaABC, $\Delta m s c K, \Delta m s c S 1$, $\Delta m s c S 2, \Delta m s c S 3)$.

\section{Impact of MS channel deletion on ectoine excretion}

Ectoine excretion and glucose consumption were measured for H. elongata KB2.13 and the deletion mutant KB2.13MSC which is devoid of all MS channels. When grown in MOPS medium at $0.7 \mathrm{M}$ and $2 \mathrm{M} \mathrm{NaCl}$, respectively, the strains KB2.13 and KB2.13-MSC consumed identical amounts of glucose and displayed the same growth behavior. The MS channel mutant KB2.13-MSC exported less ectoine to the growth medium during the 10-h experiment. However, only a relatively small reduction of the final ectoine concentration was observed, even though all MS channels had been deleted. The excretion of ectoine 

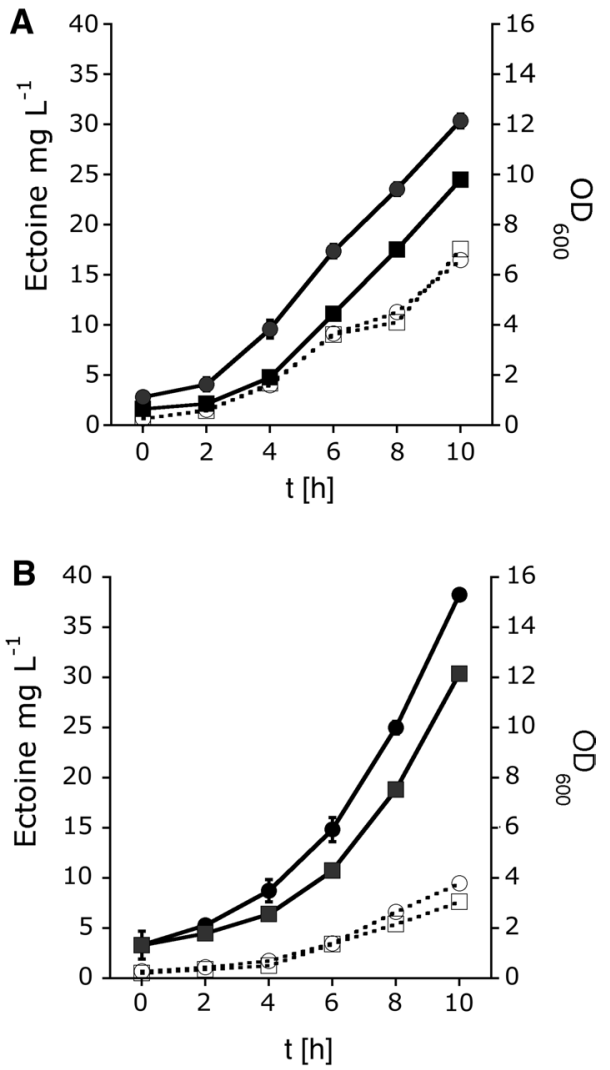

Fig. 6 Ectoine excretion from MS channel mutant KB2.13-MSC compared to parental strain $\mathrm{KB} 2.13$ at salinities of $0.7 \mathrm{M} \mathrm{NaCl}$ (a) and $2 \mathrm{M} \mathrm{NaCl}$ (b). Ectoine concentration in growth medium was measured from ectoine excretion strain KB2.13 (black circle) and KB2.13-MSC (black square) and growth for KB2.13 (white circle) and KB2.13-MSC (white square) was monitored $\left(\mathrm{OD}_{600}\right)$ for $10 \mathrm{~h}$. Mutant strain KB2.13-MSC, which lacks all MS channel genes, still exported approximately $80 \%$ of the ectoine compared to KB2.13. Data presented are from three independent experiments (three biological replicates). Each experiment was measured three times (three technical replicates)

was only $19 \%$ (at $2 \mathrm{M} \mathrm{NaCl}$ ) and $21 \%$ (at $0.7 \mathrm{M} \mathrm{NaCl}$ ) lower than for the parental strain (Fig. 6). Thus, even though MS channels of $H$. elongata are an export route for ectoine, they are only of minor importance for this process. Approximately $80 \%$ of the ectoine was released from the cell via a major, yet enigmatic pathway.

\section{Discussion}

MS channels play an essential role in the regulation of turgor in bacteria (Krämer 2010). H. elongata can maintain turgor pressure across a wide range of osmolarities. The maintenance of turgor pressure requires bacteria to adjust their internal solute pools in response to changes in osmolarity (Booth and Louis 1999; Morbach and Kramer 2002; Wood et al. 2001). Increased expression of transport systems and enzymes ensures that high concentrations of compatible solutes can be established and maintained. We set out to determine the role of mechanosensitive channels for osmoadaptation and for excretion of the compatible solute ectoine in $H$. elongata. For this purpose, we analyzed the transcription of MS channel genes, ectoine excretion and growth behavior in the wildtype strain and a deletion mutant lacking all MS channels under steady state conditions and during osmotic shock.

H. elongata possesses in total four genes encoding MS channels, which all belong to the MscS-family. The main role assigned to MS channels in cell physiology is to act as emergency valves upon hypoosmotic shock releasing excess of organics solutes and ions to the medium (Levina et al. 1999). Stokes and co-workers stated that in cells exposed to hypoosmotic shock, MS channels must be activated on a millisecond time scale to prevent damage to cell integrity (Stokes et al. 2003). De novo gene expression cannot modulate the levels of MS channel proteins on this time scale, suggesting that MS channel expression might be induced when cells are exposed to high osmolarity to prepare for the eventuality of hypoosmotic stress (Stokes et al. 2003). However, our results revealed that MS channel expression in $H$. elongata is regulated differently. We assessed the transcript levels in osmotically adapted cells at low $(0.1 \mathrm{M})$, medium ( $1 \mathrm{M})$ and high salt $(2 \mathrm{M})$ and observed that the MS channel genes $m s c S 3$ and $m s c K$ were downregulated, when the salt concentration increased from 0.1 to $1 \mathrm{M} \mathrm{NaCl}$ and $m s c K$ was even further downregulated when salinity reached $2 \mathrm{M} \mathrm{NaCl}$. Gene $m s c S 1$ was downregulated when salinity increased to $2 \mathrm{M} \mathrm{NaCl}$, while changes in transcription of $m s c S 2$ did not reach significance. It must be stressed that the transcription of $m s c S 2, m s c S 3$ and $m s c K$ is low compared to $m s c S 1$ at $1 \mathrm{M} \mathrm{NaCl}$ (Fig. 1). Quantitative analysis of the membrane proteome of $H$. elongata performed by Raschke uncovered a decreased protein content of $\mathrm{MscK}, \mathrm{MscS} 1$ and MscS3 at high salinity (Raschke 2020), which supports our findings. The proteome and transcription data collected for H. elongata do not support the idea that MS channel expression rises with salinity to better prepare the cells for the eventuality of hypoosmotic shock caused, for instance, by rainfall. Our analysis of transcription levels upon osmotic shock supports the observations made with salt-adapted cells. The MS channel genes were downregulated or not regulated at all after hyperosmotic shock and upregulation was never observed.

The finding that the $m s c S$ genes are rather downregulated is also in agreement with the growth behavior of the MS channel mutant of $H$. elongata. Mutant MSC-1324, which is lacking all MS channels, grew faster at higher salinity compared to the wildtype. Here, the lack of all MS channels seems beneficial and might save energy, which is otherwise 
required to balance ion and osmolyte flow over the membrane via MS channels.

The importance of MS channels for osmoadaptation in H. elongata was demonstrated by hypoosmotic shock from 1 to $0.1 \mathrm{M} \mathrm{NaCl}$, where 100 times less MSC-1324 mutant cells survived compared to the wildtype. In comparison to other bacteria, however, wildtype cells of $H$. elongata have a low survival rate of $10 \%$. The downshock we applied was corresponding to the withdrawal of $900 \mathrm{mM} \mathrm{NaCl}$. B. subtilis proved rather resilient and roughly $100 \%$ cells survived a shock equivalent to the withdrawal of $760 \mathrm{mM}$ $\mathrm{NaCl}$ (Hoffmann et al. 2008). And approximately $90 \%$ of E. coli cells survived shocks equivalent to the withdrawal of 300-500 mM NaCl (Levina et al. 1999). C. glutamicum seems to be more susceptible to hypoosmotic downshock, but still $25 \%$ of the cells stayed alive after withdrawal of $750 \mathrm{mM} \mathrm{NaCl}$ (Nottebrock et al. 2003). Whether the different cell wall design (e.g., B. subtilis) or the lesser stress being applied resulted in the better survival of the nonhalophiles is a matter of speculation. It must be noted that after downshock, E. coli, C. glutamicum and B. subtilis ended up in favorable osmotic conditions, while the withdrawal of $\mathrm{NaCl}$ imposed an additional stress of low salt $(0.1 \mathrm{M} \mathrm{NaCl})$ on cells of $H$. elongata.

When bacterial cells are adapting to a hyperosmotic environment, compatible solutes like ectoine are accumulated internally to a concentration corresponding to the external osmolality (Bursy et al. 2008; Kuhlmann and Bremer 2002). How the cell matches the internal solute concentration to the external salt concentration is still not quite understood. Important to the understanding of this regulatory problem is the fact that the bacterial cells are releasing compatible solutes to the outside. This observation was made first with $E$. coli cells that were loaded with radioactively labelled glycine-betaine and ectoine, respectively. The radioactive solutes were released from the cell and unlabeled glycine-betaine and ectoine, respectively, were recycled from the medium (Jebbar et al. 1992; Lamark et al. 1992). Subsequently, similar observations were made for other bacteria such as Synechocystis sp. (Hagemann et al. 1997). That the release of compatible solutes might be linked to compatible solute synthesis came from the observation made with a $H$. elongata transport mutant. Inactivating $\mathrm{Tea} \mathrm{ABC}$, the only ectoine uptake system in $H$. elongata, created an ectoine excretion and ectoine overproducing mutant (Grammann et al. 2002). We concluded that the loss of ectoine and its subsequent uptake by ectoine-specific transporter TeaABC serves as a signal for the regulation of ectoine synthesis. Increasing the ectoine concentration by synthesis will lead to water influx and an increase in turgor pressure, which could trigger stretch-sensitive export channels or carriers for solutes. Transport of exported ectoine back into the cell via TeaABC will downregulate ectoine synthesis. The proposed regulation mechanism would allow for an oscillation of the cytoplasmic ectoine level closely above and below the threshold needed to open the solute-specific export channels and carriers, respectively.

There are in principle four different ways by which compatible solutes can exit the bacterial cell, namely, by (i) passive diffusion across the membrane, (ii) reversal of compatible solute uptake systems, (iii) efflux via (more or less unspecific) channels including MS channels (channel model), and (iv) efflux via carrier systems with either broad or narrow substrate specificity (carrier model). Passive diffusion across the membrane is no plausible mechanism in our view for the release of bacterial compatible solutes. There is also (to our knowledge) no support by proven examples for the release of compatible solutes by reversal of uptake transporters and this can be ruled out for $H$. elongata as the transporter in question (TeaABC) was absent in the investigated strain.

The Krämer group collected evidence that $C$. glutamicum applies a pump and leak mechanism in fine tuning the internal glycine betaine concentration by cooperation of an active glycine betaine uptake via osmoregulated transporter BetP and a passive, but regulated efflux via MS channels (Börngen et al. 2010). For releasing the compatible solute glycinebetaine, $C$. glutamicum employs MscCG, a mechanosensitive channel of the MscS-type. MscCG is the major export route for glutamate in C. glutamicum and in addition to its osmotic function, it serves as a metabolic valve (Nakayama et al. 2018b). Compared to canonical MscS, it has a long $\mathrm{C}$-terminal extension that has an additional C-terminal transmembrane domain. This extension, including its additional transmembrane domain, is responsible for the unusual gating mechanism of MscCG (Nakayama et al. 2016) with a lower activation threshold and slow closing. In contrast, canonical $\mathrm{MscS}$ channels gate in response to hypoosmotic shock and seemingly follow the Jack-in-the-box mechanism (Malcolm et al. 2015), which does not fit for MscCG as a consequence of structural adaptations (Nakayama et al. 2019, 2018a).

The export of compatible solutes via channels as described for $C$. glutamicum is not a universal mechanism. Evidence for the existence of compatible solute efflux systems other than channels has been provided for several bacteria. For Salmonella enterica (serovar Typhimurium) and Lactobacillus plantarum it was shown that compatible solutes are released from the cell by a carrier-mediated process rather than by channels (Glaasker et al. 1996; Koo et al. 1991). S. enterica cells loaded with the compatible solute glycine betaine lost glycine betaine upon chemical modification of an unknown efflux system (Koo et al. 1991). Glaasker and coworkers provided evidence for an independent glycine-betaine efflux system in L. plantarum, which can be distinguished from MS channels by its kinetic parameters 
(Glaasker et al. 1996). Upon osmotic downshock, glycinebetaine is rapidly released via a MS channel-like mechanism (osmotic valve) and more slowly by the second system (metabolic valve). The second system is responsible for glycine-betaine efflux in osmotically adapted cells and allows a downhill efflux via a carrier-like mechanism (Glaasker et al. 1996). A channel-independent export of compatible solutes was also described for B. subtilis and E. coli. In B. subtilis none of the known MS channels of the MscL- and MscStype participated in export of the endogenous compatible solute proline (Hoffmann et al. 2012), and in osmotically adapted $E$. coli cells hydroxyectoine export is independent of MS channels as well (Czech et al. 2016). We are not aware that the export systems have been identified in any of these organisms. However, Bay and Turner (2012) brought forward some indirect evidence (loss-of-growth phenotype under hyperosmotic conditions) that small multidrug resistance (SMR) transporter protein EmrE might be responsible for the export of glycine betaine and choline in E. coli.

The data provided by us in the present study draw a similar picture and revealed a MS channel independent export of ectoine from $H$. elongata cells. Specific efflux systems for various types of compounds, in particular amino acids, are already known for different microorganisms (Eggeling and Sahm 2003; Hori et al. 2011; Trötschel et al. 2005). Hence, H. elongata might possess a carrier-mediated efflux system, which is either a general compatible solutes exporter or a more specific system for the export of ectoine and eventually hydroxyectoine.

Still the question remains how an efflux system for compatible solutes is linked to osmolarity and can sense the internal solute concentration. For Dickeya dadantii (Erwinia chrysanthemi) a putative sensor protein was described that enables the cell to specifically measure the internal glycine betaine concentration and the extracellular salt concentration (Touzé et al. 2001). Inactivation of the sensor, which shares some similarities with MscK, resulted in loss of glycinebetaine from the cell but not of other compatible solutes. The ectoine excretion assay, which we developed earlier (Grammann et al. 2002) and was also applied in this study (data not shown), will be a helpful tool in identifying genes encoding such sensors and compatible solute export carries, respectively.

Acknowledgements Open Access funding provided by Projekt DEAL. We gratefully acknowledge the financial support from the PhD program of BAM, and we thank Ines Wedell for valuable technical assistance.

\section{Compliance with ethical standards}

Conflict of interest The authors declare no conflict of interests.

Open Access This article is licensed under a Creative Commons Attribution 4.0 International License, which permits use, sharing, adaptation, distribution and reproduction in any medium or format, as long as you give appropriate credit to the original author(s) and the source, provide a link to the Creative Commons licence, and indicate if changes were made. The images or other third party material in this article are included in the article's Creative Commons licence, unless indicated otherwise in a credit line to the material. If material is not included in the article's Creative Commons licence and your intended use is not permitted by statutory regulation or exceeds the permitted use, you will need to obtain permission directly from the copyright holder. To view a copy of this licence, visit http://creativecommons org/licenses/by/4.0/.

\section{References}

Alfaro-Espinoza G, Ullrich MS (2015) Bacterial $\mathrm{N}_{2}$-fixation in mangrove ecosystems: insights from a diazotroph-mangrove interaction. Front Microbiol 6:445. https://doi.org/10.3389/fmicb .2015 .00445

Bay DC, Turner RJ (2012) Small multidrug resistance protein EmrE reduces host $\mathrm{pH}$ and osmotic tolerance to metabolic quaternary cation osmoprotectants. J Bacteriol 194:5941-5948. https://doi. org/10.1128/JB.00666-12

Berrier C, Coulombe A, Szabo I, Zoratti M, Ghazi A (1992) Gadolinium ion inhibits loss of metabolites induced by osmotic shock and large stretch-activated channels in bacteria. Eur J Biochem 206:559-565. https://doi.org/10.1111/j.1432-1033.1992.tb169 $60 . \mathrm{x}$

Berrier C, Besnard M, Ajouz B, Coulombe A, Ghazi A (1996) Multiple mechanosensitive ion channels from Escherichia coli, activated at different thresholds of applied pressure. J Membr Biol 151:175-187

Booth IR, Louis P (1999) Managing hypoosmotic stress: aquaporins and mechanosensitive channels in Escherichia coli. Curr Opin Microbiol 2:166-169

Börngen K, Battle AR, Möker N, Morbach S, Marin K, Martinac B, Krämer R (2010) The properties and contribution of the Corynebacterium glutamicum $\mathrm{MscS}$ variant to fine-tuning of osmotic adaptation. Biochim Biophys Acta 1798:2141-2149

Brown AD (1976) Microbial water stress. Bacteriol Rev 40:803-846

Bünger J, Degwert J, Driller H (2001) The protective function of compatible solute ectoin on the skin, skin cells and its biomolecules with respect to UV radiation, immunosuppression and membrane damage. IFSCC Mag 4:127-131

Bursy J, Kuhlmann AU, Pittelkow M, Hartmann H, Jebbar M, Pierik AJ, Bremer E (2008) Synthesis and uptake of the compatible solutes ectoine and 5-hydroxyectoine by Streptomyces coelicolor A3(2) in response to salt and heat stresses. Appl Environ Microbiol 74:7286-7296

Cox CD, Nakayama Y, Nomura T, Martinac B (2015) The evolutionary 'tinkering' of MscS-like channels: generation of structural and functional diversity. Pflugers Arch 467:3-13. https://doi. org/10.1007/s00424-014-1522-2

Cox CD, Bavi N, Martinac B (2018) Bacterial mechanosensors. Annu Rev Physiol 80:71-93. https://doi.org/10.1146/annurev-physi ol-021317-121351

Czech L, Stoveken N, Bremer E (2016) EctD-mediated biotransformation of the chemical chaperone ectoine into hydroxyectoine and its mechanosensitive channel-independent excretion. Microb Cell Fact 15:126. https://doi.org/10.1186/s12934-016-0525-4

Eggeling L, Sahm H (2003) New ubiquitous translocators: amino acid export by Corynebacterium glutamicum and Escherichia coli. Arch Microbiol 180:155-160. https://doi.org/10.1007/s0020 3-003-0581-0 
Farwick M, Siewe RM, Krämer R (1995) Glycine betaine uptake after hyperosmotic shift in Corynebacterium glutamicum. J Bacteriol 177:4690-4695

Galinski EA (1995) Osmoadaptation in bacteria. Adv Microb Physiol 37:272-328

Glaasker E, Konings WN, Poolman B (1996) Glycine betaine fluxes in Lactobacillus plantarum during osmostasis and hyper- and hypo-osmotic shock. J Biol Chem 271:10060-10065. https://doi. org/10.1074/jbc.271.17.10060

Göller K, Ofer A, Galinski EA (1998) Construction and characterization of an $\mathrm{NaCl}$-sensitive mutant of Halomonas elongata impaired in ectoine biosynthesis. FEMS Microbiol Lett 161:293-300

Grammann K, Volke A, Kunte HJ (2002) New type of osmoregulated solute transporter identified in halophilic members of the bacteria domain: TRAP transporter TeaABC mediates uptake of ectoine and hydroxyectoine in Halomonas elongata DSM $2581^{\mathrm{T}}$. J Bacteriol 184:3078-3085

Hagemann M, Richter S, Mikkat S (1997) The ggtA gene encodes a subunit of the transport system for the osmoprotective compound glucosylglycerol in Synechocystis sp. strain PCC 6803. J Bacteriol 179:714-720

Hoffmann T, Boiangiu C, Moses S, Bremer E (2008) Responses of Bacillus subtilis to hypotonic challenges: physiological contributions of mechanosensitive channels to cellular survival. Appl Environ Microbiol 74:2454-2460

Hoffmann T, von Blohn C, Stanek A, Moses S, Barzantny H, Bremer E (2012) Synthesis, release, and recapture of compatible solute proline by osmotically stressed Bacillus subtilis cells. Appl Environ Microbiol 78:5753-5762. https://doi.org/10.1128/ AEM.01040-12

Hori H, Yoneyama H, Tobe R, Ando T, Isogai E, Katsumata R (2011) Inducible L-alanine exporter encoded by the novel gene ygaW (alaE) in Escherichia coli. Appl Environ Microbiol 77:40274034. https://doi.org/10.1128/AEM.00003-11

Jebbar M, Talibart R, Gloux K, Bernard T, Blanco C (1992) Osmoprotection of Escherichia coli by ectoine-uptake and accumulation characteristics. J Bacteriol 174:5027-5035. https://doi. org/10.1128/Jb.174.15.5027-5035.1992

Kempf B, Bremer E (1998) Uptake and synthesis of compatible solutes as microbial stress responses to high-osmolality environments. Arch Microbiol 170:319-330

Kindzierski V et al (2017) Osmoregulation in the Halophilic Bacterium Halomonas elongata: a case study for integrative systems biology. PLoS ONE 12:e0168818. https://doi.org/10.1371/journ al.pone. 0168818

Klähn S, Hagemann M (2011) Compatible solute biosynthesis in cyanobacteria. Environ Microbiol 13:551-562. https://doi.org/1 0.1111/j.1462-2920.2010.02366.x

Kolp S, Pietsch M, Galinski EA, Gutschow M (2006) Compatible solutes as protectants for zymogens against proteolysis. Biochim Biophys Acta 1764:1234-1242

Koo SP, Higgins CF, Booth IR (1991) Regulation of compatible solute accumulation in Salmonella typhimurium: evidence for a glycine betaine efflux system. J Gen Microbiol 137:2617-2625

Kozera B, Rapacz M (2013) Reference genes in real-time PCR. J Appl Genet 54:391-406. https://doi.org/10.1007/s13353-013-0173-x

Kraegeloh A, Kunte HJ (2002) Novel insights into the role of potassium for osmoregulation in Halomonas elongata. Extremophiles 6:453-462

Kraegeloh A, Amendt B, Kunte HJ (2005) Potassium transport in a halophilic member of the bacteria domain: identification and characterization of the $\mathrm{K}^{+}$uptake systems TrkH and TrkI from Halomonas elongata DSM $2581^{\mathrm{T}}$. J Bacteriol 187:1036-1043

Krämer R (2010) Bacterial stimulus perception and signal transduction: response to osmotic stress. Chem Rec 10:217-229. https:// doi.org/10.1002/tcr.201000005
Kuhlmann AU, Bremer E (2002) Osmotically regulated synthesis of the compatible solute ectoine in Bacillus pasteurii and related Bacillus spp. Appl Environ Microbiol 68:772-783

Kuhlmann SI, Terwisscha van Scheltinga AC, Bienert R, Kunte HJ, Ziegler C (2008) $1.55 \AA$ Structure of the Ectoine Binding Protein TeaA of the Osmoregulated TRAP-Transporter TeaABC from Halomonas elongata. Biochemistry 47:9475-9485

Kunte HJ (2006) Osmoregulation in bacteria: compatible solute accumulation and osmosensing. Environ Chem 3:94-99

Kunte HJ, Galinski EA (1995) Transposon mutagenesis in halophilic eubacteria: conjugal transfer and insertion of transposon Tn5 and Tn1732 in Halomonas elongata. FEMS Microbiol Lett 128:293-299

Kunte HJ, Galinski EA, Grammann K, Volke A, Bestvater T (2002) Verfahren zur Gewinnung von Wertstoffen aus Organismen. Austria, Belgium, Switzerland/Lichtenstein, Cyprus, Germany, Denmark, Spain, Finnland, France, Great Britain, Greece, Irland, Italy, Luxemburg, Monaco, The Netherlands, Portugal, Sweden, Turkey; Patent European Patent EP 1409707, 31.12.2008

Kunte HJ, Lentzen G, Galinski EA (2014) Industrial production of the cell protectant ectoine: protection mechanisms, processes, and products. Curr Biotechnol 3:10-25. https://doi. org/10.2174/22115501113026660037

Lamark T, Styrvold OB, Strøm AR (1992) Efflux of choline and glycine betaine from osmoregulating cells of Escherichia coli. FEMS Microbiol Lett 96:149-154

Larsen PI, Sydnes LK, Landfald B, Strøm AR (1987) Osmoregulation in Escherichia coli by accumulation of organic osmolytes: betaines, glutamic acid, and trehalose. Arch Microbiol 147:1-7

Lentzen G, Schwarz T (2006) Extremolytes: Natural compounds from extremophiles for versatile applications. Appl Microbiol Biotechnol 72:623-634. https://doi.org/10.1007/s0025 3-006-0553-9

Levina N, Tötemeyer S, Stokes NR, Louis P, Jones MA, Booth IR (1999) Protection of Escherichia coli cells against extreme turgor by activation of MscS and MscL mechanosensitive channels: identification of genes required for MscS activity. EMBO J 18:1730-1737

Lippert K, Galinski EA (1992) Enzyme stabilization by ectoine-type compatible solutes: protection against heating, freezing and drying. Appl Microbiol Biotechnol 37:61-65

Malcolm HR, Blount P, Maurer JA (2015) The mechanosensitive channel of small conductance (MscS) functions as a Jack-inthe box. Biochim Biophys Acta 1848:159-166. https://doi. org/10.1016/j.bbamem.2014.10.022

Martinac B (2001) Mechanosensitive channels in prokaryotes. Cell Physiol Biochem 11:61-76. https://doi.org/10.1159/000047793

Mikkat S, Effmert U, Hagemann M (1997) Uptake and use of the osmoprotective compounds trehalose, glucosylglycerol, and sucrose by the cyanobacterium Synechocystis sp. PCC6803. Arch Microbiol 167:112-118

Miller GL (1959) Use of dinitrosalicylic acid reagent for determination of reducing sugar. Anal Chem 31:426-428. https://doi. org/10.1021/ac60147a030

Morbach S, Kramer R (2002) Body shaping under water stress: osmosensing and osmoregulation of solute transport in bacteria. ChemBioChem 3:384-397

Nakayama Y, Becker M, Ebrahimian H, Konishi T, Kawasaki H, Kramer R, Martinac B (2016) The impact of the C-terminal domain on the gating properties of MscCG from Corynebacterium glutamicum. Biochim Biophys Acta 1858:130-138. https ://doi.org/10.1016/j.bbamem.2015.10.010

Nakayama Y, Hashimoto K-i, Sawada Y, Sokabe M, Kawasaki H, Martinac B (2018a) Corynebacterium glutamicum mechanosensitive channels: towards unpuzzling "glutamate efflux" for 
amino acid production. Biophys Rev 10:1359-1369. https://doi. org/10.1007/s12551-018-0452-1

Nakayama Y, Komazawa K, Bavi N, Hashimoto K, Kawasaki H, Martinac B (2018b) Evolutionary specialization of MscCG, an MscS-like mechanosensitive channel, in amino acid transport in Corynebacterium glutamicum. Sci Rep. https://doi.org/10.1038/ s41598-018-31219-6

Nakayama Y, Hashimoto K-i, Kawasaki H, Martinac B (2019) "Force-from-lipids" mechanosensation in Corynebacterium glutamicum. Biophys Rev 11:327-333. https://doi.org/10.1007/ s12551-019-00524-3

Nottebrock D, Meyer U, Krämer R, Morbach S (2003) Molecular and biochemical characterization of mechanosensitive channels in Corynebacterium glutamicum. FEMS Microbiol Lett 218:305-309

Ono $\mathrm{H}$ et al (1999) Characterization of biosynthetic enzymes for ectoine as a compatible solute in a moderately halophilic eubacterium, Halomonas elongata. J Bacteriol 181:91-99

Oren A (2002) Halophilic microorganisms and their environments. Cellular origin and life in extreme habitats. Kluwer Academic Publishers, Dordrecht

Penn K, Jensen PR (2012) Comparative genomics reveals evidence of marine adaptation in Salinispora species. BMC Genomics 13:86. https://doi.org/10.1186/1471-2164-13-86

Peters P, Galinski EA, Trüper HG (1990) The biosynthesis of ectoine. FEMS Microbiol Lett 71:157-162

Pfaffl MW (2001) A new mathematical model for relative quantification in real-time RT-PCR. Nucleic Acids Res 29:e45

Pfeiffer F et al (2017) Revision and reannotation of the Halomonas elongata DSM $2581^{\mathrm{T}}$ genome. Microbiologyopen 6:e00465. https ://doi.org/10.1002/mbo3.465

Pivetti CD, Yen MR, Miller S, Busch W, Tseng YH, Booth IR, Saier MH Jr (2003) Two families of mechanosensitive channel proteins. Microbiol Mol Biol Rev 67:66-85. https://doi.org/10.1128/ mmbr.67.1.66-85.2003

Raschke S (2020) Regulation zur Salzanpassung mit Auswirkungen auf den Ectoinmetabolismus in adaptierten $H$. elongata ZellenUntersuchungen im Membranproteom, Cytosolproteom und Transkriptom. Ph.D., Rheinische Friedrich-Wilhelms-Universität Bonn

Roberts MF (2005) Organic compatible solutes of halotolerant and halophilic microorganisms. Saline Syst 1:1-30

Schäfer A, Tauch A, Jäger W, Kalinowski J, Thierbach G, Pühler A (1994) Small mobilizable multi-purpose cloning vectors derived from the Escherichia coli plasmids pK18 and pK19: selection of defined deletions in the chromosome of Corynebacterium glutamicum. Gene 145:69-73

Schenk A, Weingart H, Ullrich MS (2008) Extraction of high-quality bacterial RNA from infected leaf tissue for bacterial in planta gene expression analysis by multiplexed fluorescent Northern hybridization. Mol Plant Pathol 9:227-235. https://doi.org/10.1 111/j.1364-3703.2007.00452.x

Schröter MA, Meyer S, Hahn MB, Solomun T, Sturm H, Kunte HJ (2017) Ectoine protects DNA from damage by ionizing radiation. Sci Rep 7:15272. https://doi.org/10.1038/s41598-017-15512-4
Schweikhard ES, Kuhlmann SI, Kunte H-J, Grammann K, Ziegler CM (2010) Structure and function of the universal stress protein TeaD and its role in regulating the ectoine transporter TeaABC of Halomonas elongata DSM $2581^{\mathrm{T}}$. Biochemistry 49:2194-2204

Schwibbert K et al (2011) A blueprint of ectoine metabolism from the genome of the industrial producer Halomonas elongata DSM $2581^{\mathrm{T}}$. Environ Microbiol 13:1973-1994

Stokes NR et al (2003) A role for mechanosensitive channels in survival of stationary phase: regulation of channel expression by RpoS. Proc Natl Acad Sci USA 100:15959-15964. https://doi. org/10.1073/pnas.2536607100

Sydlik U, Gallitz I, Albrecht C, Abel J, Krutmann J, Unfried K (2009) The compatible solute ectoine protects against nanoparticleinduced neutrophilic lung inflammation. Am J Respir Crit Care Med 180:29-35. https://doi.org/10.1164/rccm.200812-1911OC

Touzé T, Gouesbet G, Boiangiu C, Jebbar M, Bonnassie S, Blanco C (2001) Glycine betaine loses its osmoprotective activity in a $b s p A$ strain of Erwinia chrysanthemi. Mol Microbiol 42:87-99

Trötschel C, Deutenberg D, Bathe B, Burkovski A, Krämer R (2005) Characterization of methionine export in Corynebacterium glutamicum. J Bacteriol 187:3786-3794

Vreeland RH, Litchfield CD, Martin EL, Elliot E (1980) Halomonas elongata, a new genus and species of extremely salt-tolerant bacteria. Int J Syst Bacteriol 30:485-495

Wei L, Wedeking A, Buttner R, Kalff JC, Tolba RH, van EchtenDeckert G (2009) A natural tetrahydropyrimidine protects small bowel from cold ischemia and subsequent warm in vitro reperfusion injury. Pathobiology 76:212-220

Widderich $\mathrm{N}$ et al (2016) Strangers in the archaeal world: osmostressresponsive biosynthesis of ectoine and hydroxyectoine by the marine thaumarchaeon Nitrosopumilus maritimus. Environ Microbiol 18:1227-1248. https://doi.org/10.1111/1462-2920.13156

Wood JM (1999) Osmosensing by bacteria: signals and membranebased sensors. Microbiol Mol Biol Rev 63:230-262

Wood JM, Bremer E, Csonka LN, Krämer R, Poolman B, van der Heide T, Smith LT (2001) Osmosensing and osmoregulatory compatible solute accumulation by bacteria. Comp Biochem Physiol A Mol Integr Physiol 130:437-460

Wood JM, Culham DE, Hillar A, Vernikovska YI, Liu F, Boggs JM, Keates RA (2005) A structural model for the osmosensor, transporter, and osmoregulator ProP of Escherichia coli. Biochemistry 44:5634-5646

Zaccai G et al (2016) Neutrons describe ectoine effects on water $\mathrm{H}$-bonding and hydration around a soluble protein and a cell membrane. Sci Rep 6:31434. https://doi.org/10.1038/srep31434

Publisher's Note Springer Nature remains neutral with regard to jurisdictional claims in published maps and institutional affiliations. 